\title{
Ebola doctor reveals how infected Americans were cured
}

Techniques used in the US to treat symptoms and subdue the virus in patients could work overseas, Bruce Ribner says.

Dina Fine Maron

28 August 2014

A Q\&A from Scientific American.

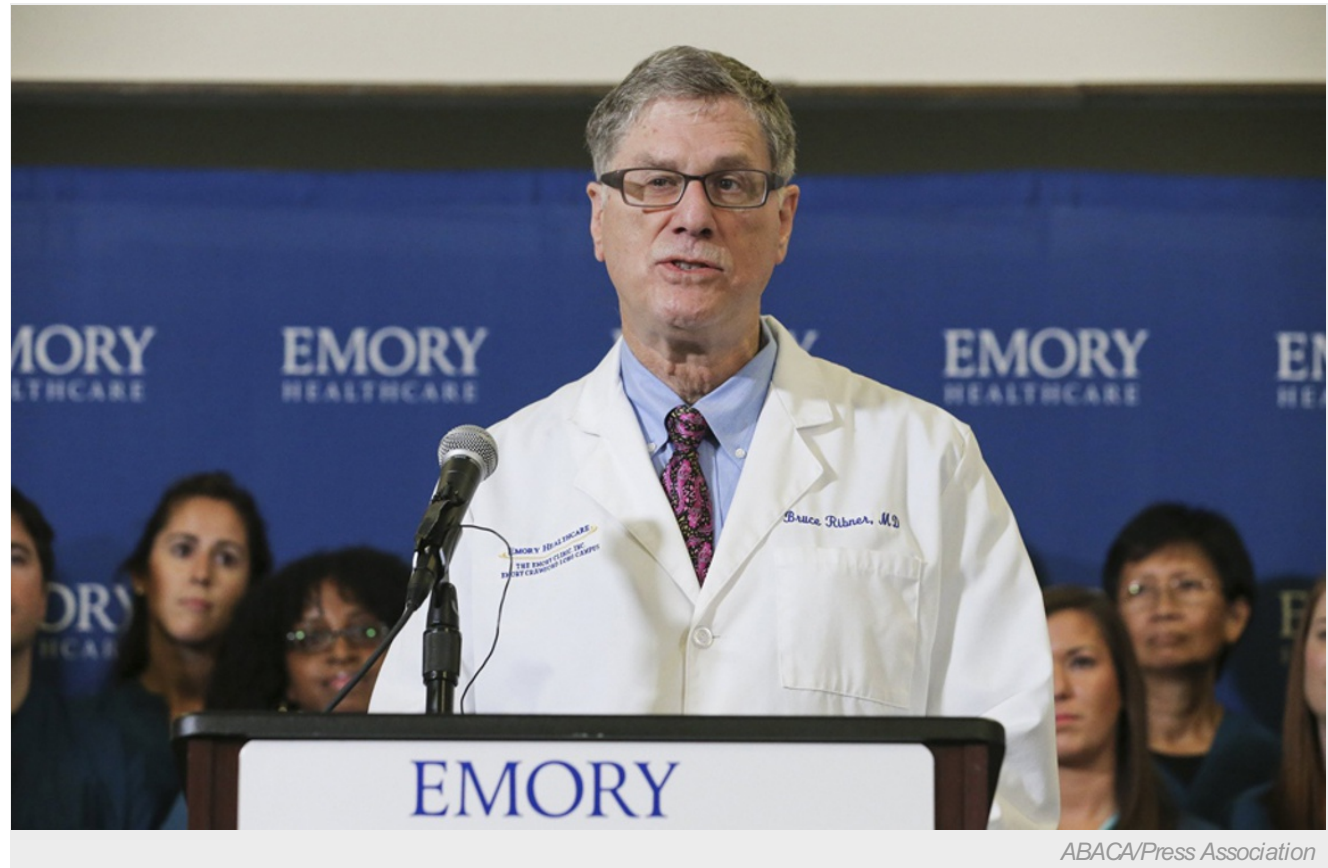

Bruce Ribner discusses the discharge of Kent Brantly and Nancy Writebol at a 21 August press conference, after the two were successfully treated for Ebola.

Last week two American aid workers who had contracted Ebola while working in west Africa were released from a US hospital and pronounced "recovered". They had been flown to Emory University Hospital in Atlanta, Georgia, from Liberia earlier this month to receive care in the hospital's specialized infectious disease unit. Kent Brantly, a physician with the humanitarian group Samaritan's Purse, and missionary Nancy Writebol, of SIM USA, beat the strain of the disease they had contracted, which kills $52 \%$ of its victims (see 'World struggles to stop Ebola').

Bruce Ribner, medical director of the hospital's Infectious Disease Unit, sat down with Scientific American to explain how the two Americans were cared for, the lessons that could be applied to help patients across Africa and why the hysteria over flying the two individuals back to the US was unfounded.

[An edited transcript of the interview follows.]

\section{Are Brantly and Writebol now immune to the Zaire strain of Ebola?}

In general, patients who have recovered from Ebola virus infection do develop a very robust immunity to the virus. They develop antibodies against the virus and they also develop cell-mediated immunity — the lymphocytes important to form viral control of pathogens. In general, the finding is it's basically like being immunized - it would be unusual to get infection with the same strain.

\section{Will that immunity afford them protection against other strains of Ebola?}

We are still evaluating that in our two patients. Cross-protection is not quite as robust. There are five strains of Ebola viruses. Even though that data is not great, the feeling is there is potential for being infected if you go to a different part of Africa and get exposed to a different strain. 
We are going to be following those two patients as outpatients, and as part of our evaluation they have agreed to undergo additional testing so we can better understand immunity to Ebola virus. We are meeting with them periodically.

\section{SCIENTIFIC AMERICAN" \\ More from Scientific American.}

What sort of lessons has Emory learned from caring for these two people that would be transferrable to patients in west Africa?

We are not being critical of our colleagues in west Africa. They suffer from a terrible lack of infrastructure and the sort of testing that everyone in our society takes for granted, such as the ability to do a complete blood count — measuring your red blood cells, your white blood cells and your platelets — which is done as part of any standard checkup here. The facility in Liberia where our two patients were didn't even have this simple thing, which everyone assumes is done as part of your annual physical.

What we found in general is that among our Ebola patients, because of the amount of fluid they lost through diarrhea and vomiting, they had a lot of electrolyte abnormalities. And so replacing that with standard fluids [used in hospital settings] without monitoring will not do a very good job of replacing things like sodium and potassium. In both of our patients we found those levels to be very low. One of the messages we will be sending back to our colleagues is: Even if you don't have the equipment to measure these levels, do be aware this is occurring when patients are having a lot of body fluid loss.

Our two patients also gained an enormous amount of fluid in their tissues, what we call edema. In Ebola virus disease there is damage to the liver and the liver no longer makes sufficient amount of protein; the proteins in the blood are very low and there is an enormous amount of fluid leakage out into the tissues. So one of the takeaway messages is to pay closer attention to that and perhaps early on try to replace some of these proteins that patients' livers lack.

\section{Considering how limited resources are in some of these facilities, could health care workers really act on this information?}

I think the world is becoming aware that issues like this are not going to go away. The developed countries of the world will have to do our part to assist our colleagues with less-developed infrastructure to care for sick people. I think one of the messages that is going out from many sources is we really have to help countries such as the ones involved in this outbreak to develop their medical infrastructure. Hopefully in five years they will have this infrastructure.

\section{You have said that you are helping to develop new Ebola care guidelines based on your} experience. How will those be disseminated?

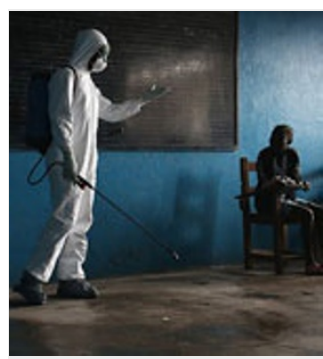

Nature special: Ebola outbreak in West Africa

We have several articles that we have submitted to major medical journals, which are read overseas, where we will be pointing this out. We are working with several government agencies, including the US State Department, to help them come up with lessons learned guidelines which they will distribute in turn to other countries. It is our goal to help our colleagues overseas.

\section{Alternatively, what lessons did you learn from those health care workers?}

Mostly the clinical course of the patients - much like any physician sending a patient to a referral center. They admitted they knew they were kind of flying blind. They'd say, "This is what we observed, but we had no way to test it."

\section{The World Health Organization [WHO] maintains that patients can continue to be infectious via their sexual fluids for several months after recovery. What did you recommend to Brantly and Writebol?}

There are data that go back several decades — over several outbreaks — that suggest when you have individuals that have recovered from Ebola virus infection they may still be shedding nuclear material [genetic material from the virus which could potentially help spread it] in semen in males and vaginal secretions in females — and also, potentially, in urine. People have done this by doing assays looking specifically at the nuclear material of the virus. There has been very little attempt to demonstrate if this is viable virus that these individuals are shedding. It's important when looking at epidemiological investigations that no one has been able to show people shedding these nuclear materials as a source of infection after they are discharged.

Looking at Ebola survivors who were discharged and successfully resolved the infection, following up several months later and evaluating their family members, there has never been any evidence that family members became infected. A lot of the thinking now is this probably was not live and is not important in terms of control of infection. We did give both of our patients the standard recommendations, which are contained on the CDC [US Centers for Disease Control and Prevention] website - not having unprotected sex for three months. 


\section{How many doctors and nurses were on your team caring for these two Ebola patients?}

Twenty-one nurses, five physicians, and we had the support of hundreds. Just making sure all the disposables coming out of those rooms were sterilized before we put them on the federal highway system, for example - we had to certify to the contractor that takes our regulated medical waste that it didn't have active Ebola virus inside it. We didn't have the equipment to handle all of the waste but in two hours facilities brought in industrial autoclaves [which sterilize materials with extreme heat] to replace the system that we had. We would have been drowning in garbage without them.

It has been reported that Brantly received a blood transfusion from a recovered patient. What role might that have played and is it being tried in other contexts?

I wouldn't be able to tell you what I read in his chart. The most accurate thing to say is, we don't have a clue [what role a blood transfusion could play]. It's not part of our standard treatment in our country. We wouldn't have any idea whether he benefited or it was detrimental.

Are current diagnostics to identify Ebola virus disease adequate for this outbreak?

Certainly in the United States they are adequate. The major way one would diagnose Ebola virus disease is through a process called PCR, or polymerase chain reaction, where you take the patient's blood, put it in a machine and it tells you in a few hours if the nuclear material from the Ebola virus is present. CDC is doing that for patients coming back from infected areas where virus is a potential. There are a number of labs, both local and courtesy of CDC, that are doing this testing in west Africa, and my sense is it's not that difficult to get it done.

This past week WHO announced that one of its workers has been infected with Ebola virus disease and that person was given the option of being sent to a different country for treatment. A British nurse also contracted the virus and went home to the UK for care. What's the value of getting treated elsewhere?

Given that there is no treatment for Ebola virus disease, the main intervention that will determine if someone lives or dies with this infection is supportive care: The ability to replace fluid and electrolytes if a patient is losing them. The ability to replace platelets if that count is low and a patient is starting to bleed. The ability to replace protein in the blood that may be deficient. A developed country has the capability because of our infrastructure to provide that level of support is at a much higher level than a hospital dealing with patients in west Africa.

"We are a long way from being able to say that someone that received ZMapp benefited"
Among the handful of patients that received the experimental drug ZMapp, some have died. Considering the mortality rate for the current Ebola strain is almost $50 \%$, what can we say about ZMapp?

Experimental drugs are experimental drugs because we don't know if they will work. That is true both with the preparations patients received in Liberia and other preparations that are being considered for treating patients with this infectious disease. We are a long way from being able to say that someone that received one of these agents benefited, it had no impact or it may be that their outcome may be impeded. Until we have good studies looking at outcomes of patients who received these medications, compared to patients who didn't receive them, we should be very cautious.

I would go further to say that there is a fair amount of almost hysteria and people feeling they must have these preparations to survive. In the past, people thought they needed agents for treatment, and the agents actually turned out to impair people's ability to survive. The focus should remain on aggressive intensive care and the ability to correct abnormalities metabolically, rather than receiving any magic vaccine or product that may or may not improve survival.

For example, there used to be a belief that patients who had bacterial sepsis did much better if you gave them high doses of steroids. Now we know that these may be detrimental instead of beneficial. We know now since we've done the studies. Again, it was one of those things where people felt like, "Yeah, this should be," but when they did the study in randomized patients they found it didn't work at all.

As you know, two upcoming clinical trials will be looking at potential Ebola vaccines, and there are also a variety of experimental therapies that are being discussed in the US and elsewhere beyond ZMapp. How should such information be coordinated? Does there need to be an entity overseeing that?

Given that we have multiple countries I don't know that you can have any one entity. It's tricky enough having the FDA [US Food and Drug Administration] monitor what is going on in the United States. Clearly if you are talking about Canadian studies or European products, I don't know that there is any entity that can provide that sort of coordination. My guess is that most of the manufacturers are 
An ethics panel from WHO recently said that it is ethical to give out experimental treatments to Ebola patients, but it has not yet specified who should have priority in such circumstances, or how such drugs should be doled out. They are taking up that issue at a meeting next week. What's your thought?

I think it's certainly ethical to study experimental biologicals and vaccines but we have to be extremely cautious. It's not as though we have something that we know works. To say that anyone is withholding products implies we know that there's a benefit, which gives me pause because we are a long long way from demonstrating that these offer any benefit in humans.
"It's not as though we have something that we know works. To say that anyone is withholding products implies we know that there's a benefit"

\section{Is there anything you would like to add about insights you learned from your Ebola patient care?}

The major thing I hope people have appreciated is there was a lot of anxiety, a lot of negative comment about our bringing these two patients back to our facility to care for them. Most of that we attribute to poor education, and l'm hoping that since we were successful in helping them resolve their infections it helps to dispel the idea that this is a disease that by nature has to be fatal. As we have been saying all along, we feel that the high fatality rates in developing parts of the world where this infection occurs are because of the lack of resources. We had always felt that the survival of patients with proper support would be a lot better than in developing countries.

The other thing I would hope we would get across to the public is that this is a disease where we don't have to have a lot of secondary infections - if we follow standard infection-control procedures. We had 26 people giving direct patient care to these patients and we did not have any secondary infections at all, and that's as we expected.

We were using contact precautions and droplet precautions. Fortunately, we don't have to go to that level of protection [wearing protective full-body suits like in west Africa]. You wear whatever you need so that the blood and body secretions don't come into contact with you, depending on the quantity of fluids. We used gowns and gloves and foot coverings of the health care workers in order to prevent contact with the body materials of these individuals. Our approach was what CDC recommends: you wear a mask and goggles or a face shield to prevent that infection. Some of the nurses spending three to four hours in patients' rooms were more comfortable wearing hoods than masks and face shields, though those would have been adequate. We can manage care with minimal chance for secondary spread. It's not as though we brought the plague to American shores.

Nature | doi:10.1038/nature.2014.15791 